\title{
Exploring the relationships between different types of environmental regulations and environmental performance: Evidence from China
}

Ruiqian Li

Accounting School, Harbin University of Commerce, No. 1 Xuehai Street, Songbei District, Harbin, China

Postcode: 150028

Ph: 0086-15765537082

Emai1: 1iruiqian0451@163.com

Ramakrishnan Ramanathan (Corresponding author)

Business \& Management Research Institute, University of Bedfordshire, Putteridge Bury Campus, Luton, Bedfordshire, LU2 8LE, United Kingdom

Ph: 00441582743516

Fax: 01582482689

Email: ram.ramanathan@beds.ac.uk

Abstract: The literature on the relationship between environmental regulations (ERs) and environmental performance (EP) of firms has largely ignored consideration of different types of ERs. This study uses the literature to differentiate three types of ERs (command-and-control ERs, market-based ERs and informal regulations) and investigate the positive links between different types of ERs and EP. This study further investigates (i) the potential non-linear relationships and (ii) whether the specific ERs-EP link varies across different regions of China (Eastern and Inland). The results provide support for considering different types of ERs, while there is no evidence of a positive relationship with EP when ERs are taken together; there is evidence of a non-linear relationship between command-and-control ERs and EP, and, market-based ERs and EP. The relationship between informal regulations and EP is neutral. In addition, the link between market-based ERs and EP varies across two regions, whereas the link between command-and-control ERs and EP, and the link between informal regulations and EP do not vary across different regions. The results highlight the differing emphasis of enforcing regulations in various parts of China, and provide some valuable implications.

Keywords: environmental regulations; environmental performance; non-linear relationship; China; regional perspective

1. Introduction 
Over the past decades, China has been experiencing rapid economic growth rate and has become the world's second largest economy in 2010. However, the accelerated development process of economy has also resulted in significant environmental issues as the growth model in China now is still extensive and unsustainable (Xie et al., 2017). For instance, China has frequently experienced the hazy weather in Eastern and northeastern regions (Zhao et al., 2016) and environmental incidents have occurred frequently in recent years (Tong, 2009). How to realize the coordinated development of economy and the environment has attracted more and more attention from the government, academics and practitioners (Jiménez, 2005).

Environmental regulations (ERs) can be regarded as an important way to reduce the effects of economic activity on the natural environment (Blohmke et al., 2016; Yu et al., 2017). ERs is defined as "a set of characteristics for government environmental policies aimed at mitigating a firm's impact on the natural environment and creating a context where a firm will engage in environmental innovation" (Eiadat et al., 2008, p. 134). Since the great importance of ERs, governments worldwide all try to establish a sound and mature environmental governance system (Picazo-Tadeo and García-Reche, 2007). Generally, ERs can be divided into three different types, namely command-and-control ERs (CMCER), market-based ERs (MBER) and informal regulations (INFER) (Xie et al., 2017; Zheng and Shi, 2017). Moreover, CMCER and MBER can be treated as formal regulations. With respect to INFER, they have become another big driver of environmental protection and exert positive effects on firms' behavior (Zhang et al., 2008). INFER can be a useful supplement to affect firms' environmental practices, especially when formal regulations are weak or absent (Féres and Reynaud, 2012). However, INFER are not imposed by the government, but depend on public environmental awareness (Wesselink et al., 2011; Xie et al., 2017).

The importance of ERs has not only attracted the attention from the government but also scholars. Many scholars have investigated the impacts of ERs, such as the impacts of ERs on innovation, on competitive advantages, on financial performance or productivity (Testa et al., 2011). Most of these studies stem from Porter Hypothesis. For the government, one main purpose of enacting and implementing a series of ERs is to reduce negative environmental impacts and improve environmenta quality (Dasgupta et al., 2001). However, the empirical results of the impacts of ERs on EP are inconclusive. All possible results including positive, neutral and 
negative impacts have been found (Camisón, 2010; Féres and Reynaud, 2012). Besides, scholars also divide ERs into different types and study whether different types of ERs have heterogeneous impacts on EP (Féres and Reynaud, 2012; Zhao et al., 2015a). Furthermore, a few scholars also explore the potential complex link between ERs and EP. They have taken some organizational variables that may affect the ERs-EP link into consideration and investigate whether these variables can moderate or mediate the focal link (Guo et al., 2017; Yu et al., 2017). All these inclusive results further promote us to think about what the real relationship between ERs and EP is and if ERs can improve EP directly or not. If not, how to exert their positive impacts on EP as the original purpose of the government aims to.

In this paper, the research questions are studied from Chinese provincial-level. We collect relevant data from different statistical yearbooks. 30 provinces are included and the time periods cover from 2004 to 2014. The first contribution of our research is to provide more empirical evidence from an emerging country as scholars have pointed out most of prior studies focus on US or European context (Horváthová, 2010; Muhammad et al., 2015).

Besides, extant literature is rather limited to distinguish the different impacts of different types of ERs (Xie et al., 2017). The form of ERs can be important in determining the nature of its relationship with performance (Iraldo et al., 2011). Hence, we also differentiate three different types of ERs and attempt to investigate the nature of the links between different types of ERs and EP.

Furthermore, most of prior studies investigate the linear relationship between ERs and $\mathrm{EP}$, there is no empirical research that has investigated the potential non-linear relationships. We believe that institutional theory (IT) and stakeholder theory (ST) help to lay theoretical foundations for the potential non-linear link between ERs and EP. Hence, we not only investigate the positive links between different types ERs and EP, but also explore the non-linear links between different types of ERs and EP in this paper. To the best of our understanding, this is the first paper to examine the potential non-linear link between ERs and EP.

Lastly, it is well-known that China is a big country and different regions are significantly different in economic development level. Compared with Central and Western regions, Eastern regions are much developed in economic development (Bian et al., 2015). The significant difference in economic development may further lead to firms face different levels of pressures. It may further shape the relationship 
between ERs and EP differently. Therefore, we examine whether the link between ERs and EP varies across different regions or not. Taken together, our research extends the extant literature by providing an overall picture for exploring the nature of the impacts of ERs on EP.

To conclude, this study contributes to the literature in at least three ways. First, ours is one of the few studies focusing on a developing country in this context. Second, ours is one of the few studies to look at the relationships between different kinds of ERs and EP. Third, our study focuses both on potential linear and non-linear relationships.

The rest of the paper is organized as follows. Theoretical background and hypothesis development are included in Section 2. Section 3 presents the data, variable measurement and the methodology. Followed by results and discussions in Section 4. Conclusions are available in Section 5.

2. Theoretical background and hypothesis development

2. 1 Institutional theory and stakeholder theory

IT can be borrowed to explain the underlying connection between ERs and EP. Institutional theory suggests that organizations and their members are strongly affected by the networks in which they operate (Dimaggio and Powe11, 1983). More specifically, it can help to explain how isomorphic institutional pressures lead to common organizational practices (Delmas and Toffel, 2008). Scholars have demonstrated that institutional pressures have great impacts on shaping firms' environmental practice (Brammer et al., 2012). As a response to institutional pressures, firms have to behave properly to prevent environmental degradation so that they can obtain a "license to operate" and to gain legitimacy through external agents (Aguilera-caracuel and Ortiz-de-Mandojana, 2013; Bansal, 2005). Building upon IT, ERs, as an important part of institutional pressures, can promote firms to engage in environmental initiatives and improve environmental quality.

Another widely accepted theory that can be employed to explain the effects of ERs on EP is ST. Currently, firms face a multitude of stakeholder pressures and stakeholders have concerned more and more with environmental issues (Delmas and Toffel, 2008; Henriques and Sadorsky, 1996). In response to the increasing stakeholder pressures, it is important for firms to adopt more proactive 
environmental strategies or implement environmental practice (Yu and Ramanathan, 2015). The reasons lie in that taking stakeholders into account usually bring significant financial benefits (Wagner and Schaltegger, 2004). Moreover, firms take their relationships with stakeholders into account can help to set corporate direction and improve their organizational practices (Roberts, 1992). Therefore, stakeholder pressures could motivate companies to take more consideration of environmental issues and may encourage them to incorporate environmental practices into their management strategies (Ramanathan et al., 2014). To conclude, stakeholder pressures can lead firms to devote more resources to address environmental issues and thus improve environmental quality.

Grounding our research on IT and ST, they can explain why firms engage in environmental initiatives and reduce negative environmental impacts under the background of ever-increasing institutional pressures and stakeholder pressures. In all, both IT and ST can support the positive impacts of ERs on EP.

\section{2 Three different types of ERs and practice in China}

As noted previously, ERs can be generally divided into three different types and different types of ERs have their own characteristics.

For CMCER, the government usually sets a series of emissions limits and abatement technical standards aim to reduce emissions of the pollutants into the natural environment (Blackman, 2010). Firms whose real emissions exceed the emission standard will be fined or asked to improve the production process, or even forced to shut down (Xie et al., 2017; Yang et al., 2012). CMCER usually force firms to adopt the existing end-of-pipe technologies or switch to clean energy to reduce the amounts of emissions (Xie et al., 2017). However, CMCER are frequently criticized by the lack of flexibility in implementation (Camisón, 2010; Ramanathan et al., 2017). MBER are another widely used methods adopted by the government to regulate pollutant emissions. Although the government also establishes limits in polluting levels and applies controls and penalties, this kind of ERs is based on economic instruments and provide firms with the flexibility to adopt or invest suitable methods to reduce their negative environmental impacts (Camisón, 2010; Zhao et al., 2015b). MBER are more likely to spur firms to employ pollution prevention technologies to reduce pollutant emissions (Zhao et al., 2015b). Currently, the main instruments of MBER include taxes, pollutant charge fees, tradable permits and refund system (Jaffe et 
al., 2002; Khanna, 2001; Zhao et al., 2015b). Opposed to CMCER and MBER, which are usually treated as formal regulations, INFER do not belong to coercive policies, but depend on public environmental awareness (Wesselink et al., 2011; Xie et al., 2017). INFER also aim to modify the behavior of polluting firms then improve environmental quality. They are usually corresponding with all types of actions taken by citizens, communities or environmental NGOs or by the market such as consumers and investors (Féres and Reynaud, 2012; Zhang et al., 2008).

With the practice of ERs in China, the central government has also paid great efforts to build up a mature and sound environmental governance system to regulate firms' behavior. The first national environmental law in China came into effect in 1979. Since then, the government has accelerated the process of environmental legislation and enacted a series of environmental laws, regulations and norms at both the national level and local level (Lo et al., 2009). Currently, command-and-control regulations are the main parts of ERs (Xie et al., 2017; Zhao et al., 2015b). Apart from these CMCER, MBER have also been introduced to regulate firms' behavior. To date, pollutant discharge fees and tradable emissions are two main types of economic instruments adopted by the Chinese government. The policy of pollutant discharge fees was issued nationwide in 2003, whereas the policy of tradable emission is still in its pilot stage and this policy is only implemented in some selected cities. For formal regulations, most of these environmental policies are enacted by the central government, but local governments have great freedom in deciding how to enforce these policies (Shen et al., 2017; Zhao et al., 2015a). In terms of INFER, public environmental awareness has improved in recent years and the public is more and more involved in environmental issues. Pressures from citizens, communities, market, investors and environmental NG0s start to play more and more active roles in enhancing environmental quality in today' s China (Zhang et al., 2008; Zheng and Shi, 2017).

2. 3 The positive relationship between ERs and EP

In accordance with IT and ST, many prior studies have demonstrated the positive impacts of ERs on EP. The positive impacts of ERs on EP have been validated in several countries including in Brazil (Seroa da Motta, 2006), in China (Dasgupta et al., 2001; B. Liu et al. , 2010), in EU countries (De Brito et al., 2008), in UK (Ramanathan et al. , 2014). Besides, Baylis et al. (1998) show that ERs is the most common source 
of improving industrial EP. Esty and Porter (2002) argue that cross-country differences in EP are associated with the quality of the environmental regulatory regime in place. Kagan et al. (2003) find that tightening regulatory requirements and intensifying political pressures have brought about large improvements in EP. Gouldson et al. (2014) reveal that difference in environmental regulatory standards usually results in different industrial EP across different countries.

\subsubsection{Relationships between various types of ERs and EP}

There are some scholars further divide ERs into different types and investigate their impacts on EP. One popular way is to divide ERs into formal regulations and informal regulations. The empirical results across different countries support the positive impacts of formal and informal regulations on EP including in Indonesia by Pargal and Wheeler (1996); in Korean manufacturing plants by Aden et al. (1999) ; in UK manufacturing sectors by Cole et al. (2005); and in Brazilian manufacturing firms by Féres and Reynaud (2012). Besides, Mendes and Santos (2008) show that economic instruments such as stringent emission charges and European Union Emissions Trading Scheme are better instruments for curbing emissions from air transport. Camisón (2010) demonstrate that both cooperative and individual auto-regulation can spur firms with a more advanced environmental adaptation and consequently with a high EP. Zhao et al. (2015a) indicate that market-based regulations and government subsidies have positive impacts on $\mathrm{C} 02$ reduction.

From the theoretical perspective, both IT and ST can help to explain why firms adopt environmental practice and reduce their adverse impacts on the natural environment. They can further suggest the positive impacts of ERs on EP.

Overall, both CMCER and MBER enacted and enforced by the government attempt to regulate firms' behavior and protect the environment (Dasgupta et al., 2001). Meanwhile, INFER are also another big driver for firms to engage in environmental initiatives and help to improve EP (Liu et al., 2010; Wesselink et al., 2011; Zhang et al., 2008). Hence, we posit our hypotheses as follows.

H1: There is a positive relationship between ERS and EP.

H1a: There is a positive relationship between CMCER and EP.

H1b: There is a positive relationship between MBER and EP.

H1c: There is a positive relationship between INFER and EP. 
2. 4 The non-linear relationship between ERs and EP

Apart from the positive link, previous studies also suggest the neutral or negative link between ERs and EP. Anton et al. (2004) find that regulatory and market-based pressures do not have a direct impact on toxic releases but an indirect effect by encouraging institutional changes in the management of environmental concerns. Kassinis and Vafeas (2006) reveal that regulatory stakeholders have no relation between congressional district voting records and toxic emissions. Zhang et al. (2008) demonstrate that regulatory system does not have positive impacts on EP, especially when firms meet the basic compliance requirement. Camisón (2010) indicates that the effectiveness of coercive regulation in promoting environmental adjustment in firms is negative. Agan et al. (2013) argue that government regulations alone are not an effective way to deal with environmental pollution and climate change. Guo et al. (2017) claim that ERs has direct negative impact on regional green grow performance. Graafland and Smid (2017) reveal that perceived social license pressure is a stronger stimulus than government regulation in improving EP.

Some scholars also investigate the potential indirect link between ERs and EP. Some organizational variables have been incorporated into the research framework to investigate their moderating or mediating effects on the focal link. These moderators or mediators include environmental management system (Iraldo et al., 2009; Phan and Baird, 2015), environmental investment or innovation (Böhringer et al., 2012), environmental innovation strategy (Yu et al., 2017), technological innovation (Guo et al., 2017), among others.

Hence, the relationship between ERs and EP may be more complex than simple positive. As noted previously, the government aims to protect the environment and improve environmental quality via different environmental policy instruments (Horbach et al. , 2012). However, laxer ERs cannot affect firms' behavior effectively as firms may just meet the minimum compliance requirement of ERs. Some firms may even pay the penalties directly, especially when the compliance cost is much higher than penalty cost (Zhang et al., 2008). Besides, local governments have great freedom in deciding how to implement ERs (Shen et al., 2017; Zhao et al., 2015a). The significant difference in economic development level can result in different implementation of ERs (Jiménez, 2005; Lo et al., 2009). In less developed regions, local governments may still favor economy than the environment so that ERs may not be implemented strictly and they may exert limited pressures on firms 
(Francesch-Huidobro et al., 2012; Tang et al., 2003). What is more, pressures from citizens, communities, investors, customers, and environmental NGOs in less developed regions can be weak as well (Xie et al., 2017). Due to the limited pressures ERs exert, they cannot affect firms' behavior positively. Firms may still pay more attention to economic development and ignore to protect the environment. Hence, the link between ERs and EP can be negative.

However, with the ever-deteriorating natural environment and the development of economy, stakeholders (government, communities, citizens, investors, customers and environmental NG0s) may concern more and more about environmental protection. The increasing pressures together can force the government tries to realize the coordinated development between the environment and economy (Bi et al., 2015). Consequently, the government may improve the intensity of ERs significantly and require local governments to implement ERs strictly. As a response to the increasing pressures, firms may not only meet the requirements of ERs, but also adopt more proactive technologies rather than reactive technologies to address environmental issues (Yu et al., 2017; Zhang et al., 2008). In this regard, ERs can start to exert positive impacts on EP.

From the theoretical perspective, IT and ST both suggest institutional pressures or stakeholder pressures can affect firms' environmental practice positively. However, we argue that these pressures can exert their positive impacts only after arriving at a certain level. When the pressures are limited, they cannot have significant impacts on firms' environmental practice.

In sum, ERs can have negative impacts on EP, once the intensity of ERs arrives at a certain level, ERs can play positive impacts on EP. Based on what we have discussed above, we propose the following hypotheses.

H2: There is a non-linear relationship between ERS and EP.

H2a: There is a non-linear relationship between CMCER and EP.

$\mathrm{H} 2 \mathrm{~b}$ : There is a non-linear relationship between MBER and EP.

H2c: There is a non-linear relationship between INFER and EP.

2. 5 The regional variation of the relationship between ERs and EP Given the uneven economic development level in China, Eastern regions are much developed than in Central and Western regions (Bian et al., 2015). Different economic development level can lead to local governments implement ERs differently (Jiménez, 
2005; Lo et al., 2009). For less developed regions, local governments may place a priority on economic development rather than protecting the environment. But for much developed regions, local governments may try to realize the coordinated development between economy and the environment. Hence, for the same type of ERs, local governments in less developed regions may not implement ERs strictly so that they can exert limited pressures on regulating firms' behavior, while local governments in much developed regions may implement ERs strictly and thus exert strong pressures on regulating firms' behavior (Francesch-Huidobro et al., 2012; Tang et al. , 2003). According to IT and ST, we argue that only strong enough pressures can have positive impacts on firms' environmental practice. In addition, compared with less developed regions, stakeholders such as citizens, communities, investors, customers and environmental NG0s in much developed regions can pay more attention to environmental issues (Xie et al., 2017). Hence, pressures from the public in much developed regions can be much stronger than in less developed regions. Overall, different economic development level can result in different implementation of ERs and also lead to public environmental awareness significantly different in different regions. Hence, ERs in different regions are likely to exert different levels of pressures on firms' practice and further result in the variation of the ERs-EP link across different regions. Based on the above argument, our hypotheses are posited as follows.

H3: The link between ERs and EP varies across different regions.

H3a: The link between CMCER and EP varies across different regions.

H3b: The link between MBER and EP varies across different regions.

H3c: The link between INFER and EP varies across different regions.

3. Data and methodology

\section{1 Data and sample}

In this study, we collect provincial-level data from different Chinese statistical yearbooks, including China environmental statistical yearbook, China industry economy statistical yearbook (name changed as China industry statistical yearbook after 2013), China energy statistical yearbook, China statistical yearbook on science and technology and China statistical yearbook. The research periods cover from 2004 to 2014. We exclude Tibet because of missing data. We finally include 30 
provinces, autonomous regions, city in mainland due to the availability of data (hereinafter all referred to as province). Drawing on the traditional method of geographic division, China can be divided into three main regions (Eastern regions, Central regions and Western regions) (Yang and Wang, 2013). Eastern regions consist of 11 coastal provinces, whereas the other two regions belong to Inland provinces (Hu and Wang, 2006). Besides, compared with Eastern regions, Central and Western regions are less developed and quite similar in economic development level (Bian et al. , 2015). There is no significant difference between Central and Western regions in the mean value of Per_GDP as the T-test value is insignificant $(\mathrm{t}=0.861, p=n$. s. , data from National Bureau of Statistic and authors' calculation). Hence, Central and Western regions are called "Inland regions" in this paper on the basis of geographic division. This terminology is consistent with previous studies (e. g. Wei et al. 2017; Zheng and Shi 2017). The details of the division of 30 provinces can be seen in Table 1 .

Table 1 Regions information considered in this study

\begin{tabular}{|c|c|}
\hline Regions & Provinces included \\
\hline $\begin{array}{l}\text { Eastern } \\
\text { regions }\end{array}$ & $\begin{array}{l}\text { Beijing, Tianjin, Shanghai, Liaoning, Hebei, Shandong, Jiangsu, } \\
\text { Zhejiang, Fujian, Guangdong and Hainan }\end{array}$ \\
\hline \multirow{2}{*}{$\begin{array}{l}\text { Inland } \\
\text { regions }\end{array}$} & $\begin{array}{l}\text { Heilongjiang, Jilin, Henan, Shanxi, Anhui, Hubei, Hunan and } \\
\text { Jiangxi (Central regions) }\end{array}$ \\
\hline & $\begin{array}{l}\text { Inner Mongolia, Guangxi, Gansu, Guizhou, Ningxia, Qinghai, } \\
\text { Shaanxi, Yunnan, Xinjiang, Sichuan and Chongqing (Western } \\
\text { regions) }\end{array}$ \\
\hline
\end{tabular}

3. 2 Variable measurement

Dependent variable: Environmental performance

$\mathrm{EP}$ can be defined as “measures how successful a firm is in reducing and minimizing its impact on the environment, often relative to some industry average or peer group" (Klassen and McLaughlin 1996, p. 1199). To data, many different methods have been used to capture EP. The most popular way is to use independent database provided by the third parties, such as Toxic Release Inventory (e. g. Clarkson et al., 2008; Cordeiro and Sarkis, 1997) ; Kinder, Lydenberg, Domini index (e. g. Delmas et al., 2015; Graves and Waddock, 1999; Griffin and Mahon, 1997) ; Britain’ s Most Admired 
Companies in UK (e.g. Ramanathan et al., 2015); European Pollutant Release and Transfer Register (EPRTR) (e. g. Horváthová, 2012); Australia PRTR (APRTR) (e.g. Muhammad et al., 2015); Japanese PRTR (e. g. Fujii et al., 2013; Nakao et al., 2007b). Besides, some scholars also use pollutant emissions as proxies for $\mathrm{EP}$, such as waste intensity and greenhouse gas emissions (e.g. Fujii et al., 2013; Iwata and Okada, 2011; Trumpp and Guenther, 2015) ; industry environmental emission intensity (e. g. Qi et al., 2014); aggregated index of emissions (e. g. Telle, 2006; Wagner, 2005). Furthermore, some other methods have also been used including environmental ratings or environmental certifications (e.g. Jacobs et al., 2010; Russo and Fouts, 1997); the results of questionnaire survey (e. g. Nakao et al., 2007a; Ramanathan, 2016); the adoption of environmental policy, environmental management systems or environmental strategy (e.g. Halkos and Sepetis, 2007; Thomas, 2001; Watson et al., 2004).

Basing on the concept of EP, we select several main environmental pollutants that each province releases to air, water and land to reflect their overall impacts on the natural environment in this paper. The details of environmental pollutants data collected can be seen in Table 2 .

Table 2 Environmental pollutants included in this study

\begin{tabular}{clc}
\hline Data & \multicolumn{1}{c}{ Description } & Unit \\
\hline Waste & Total volume of industrial waste water discharged & 10000 tons \\
water & Total volume of chemical oxygen demand discharged & 10000 tons \\
\hline & Total volume of industrial waste gas emissions & 100 million cu. m \\
& Total volume of industrial soot and dust emissions & 10000 tons \\
Waste gas & Total volume of industrial sulphur dioxide emissions & 10000 tons \\
& Total volume of industrial ammonia nitrogen & 10000 tons \\
\hline Waste & Total volume of industrial solid wastes discharged & 10000 tons \\
\hline
\end{tabular}

To reflect the overall environmental impacts of each province, we need to integrate all these different types of data. Here we use the comprehensive index method and follow the three step process suggested by Zhao and Sun (2016). But there are some differences. In our research, indicator $\mathrm{j}$ is measured as the industrial output value in province $i$ divided by one of the environmental pollutants mentioned above to eliminate the effect of scale. In addition, note that we study the research questions 
from provincial-level. Hence, the city-level data has been changed as provincial-level data in our study accordingly. The final calculation results are used to capture EP. Obviously, the higher EP, the better is.

\section{Independent variable: Environmental regulations}

It is also the same that scholars have employed multiple methods to measure ERs. For instance, pollution abatement costs and expenditures (e. g. Hamamoto, 2006; Jaffe and Palmer, 1997; Kneller and Manderson, 2012; Majumdar and Marcus, 2001); the questionnaire survey results (e.g. Yu et al., 2017; Zhao et al., 2015a, 2015b) ; the intensity of pollutant emissions (e. g. Shen et al., 2017; Zhao and Sun, 2016) ; Gross National Income per capita (e. g. Aguilera-caracuel and Ortiz-de-Mandojana, 2013; Pargal and Wheeler, 1996) ; the number of inspections (e. g. Iraldo et al., 2011; Telle and Larsson, 2007).

In this paper, we use the number of environmental administrative penalty cases that the government decides every year to capture CMCER. A natural logarithm is adopted to further eliminate the potential heteroscedasticity (Hu et al., 2017; Wang and Shen, 2016). For the measurement of MBER, we use pollutant discharge fees as a proxy. The reason lies in China has established a mature pollutant levying system based on pollutant discharge fees, but the policy of tradeable emissions is still in pilot stage (Xie et al., 2017; Zheng and Shi, 2017). To further eliminate the effects of different scales, pollutant discharge fees (in 10 thousand yuan) are divided by industrial output value (in 100 million yuan) in each province. With respect to the measurement of INFER, we employ the number of complaint letters on pollution and environmental related problems in this paper since local citizens and communities are more sensitive to environmental degradation (Zheng and Shi, 2017). With the popularity of the Internet and telephone, citizens can complain environmental issues via E-mail and telephone and relevant department also included this data into China environmental statistical yearbook after 2011. Therefore, the number of complaint letters on pollution and environmental related problems (including complaints received from E-mail and telephone) is used to measures INFER. A natural logarithm is also adopted to eliminate the dimensions and effects of different variances (Hu et al., 2017).

Control variables 
Several control variables are included to ensure that the relationship is not the result of other confounding factors that have been identified. All control variables are described in Table 3.

Table 3 Measurement of control variables

\begin{tabular}{|c|c|c|}
\hline Variable & Name & Measurement \\
\hline Per capita GDP & Per_GDP & $\begin{array}{l}\text { We use per capita GDP (in } 10 \text { thousand yuan/capita) to } \\
\text { control the effect of economic development level in this } \\
\text { paper. }\end{array}$ \\
\hline $\begin{array}{l}\text { Foreign direct } \\
\text { investment }\end{array}$ & $F D I$ & $\begin{array}{l}\text { We use the ratio of FDI (in } 100 \text { million USD) to GDP (in } \\
100 \text { million yuan) in each province to capture the effect } \\
\text { of FDI. }\end{array}$ \\
\hline $\begin{array}{l}\text { Energy } \\
\text { consumption }\end{array}$ & Energy & $\begin{array}{l}\text { We employ the ratio of the number of energy consumption } \\
\text { (in } 10000 \text { tce) to GDP (in } 100 \text { million yuan) in each } \\
\text { province to control the effect of energy consumption. }\end{array}$ \\
\hline $\begin{array}{l}\text { R\&D } \\
\text { expenditure }\end{array}$ & $R \& D$ & $\begin{array}{l}\text { We use the ratio of intramural R\&D expenditure (in } 100 \\
\text { million yuan) to industrial output value (in } 100 \text { million } \\
\text { yuan) in each province to control the effect of R\&D } \\
\text { expenditure in this paper. }\end{array}$ \\
\hline $\begin{array}{l}\text { Industrial } \\
\text { scale }\end{array}$ & Scale & $\begin{array}{l}\text { We use the proportion of the industrial output value (in } \\
100 \text { million yuan) to the number of industrial enterprises } \\
\text { (in unit) in each province to control the effect of scale. }\end{array}$ \\
\hline
\end{tabular}

\section{3 Model selection}

In the present paper, two econometric models are constructed to verify the hypotheses we proposed. To verify the positive link between ERs and EP, the linear regression model is used (shown in Model 1).

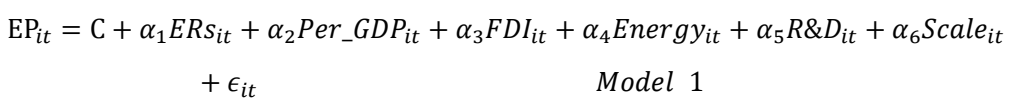

To verify the non-linear link between ERs and EP, a quadratic functional form of regression model is employed (shown in Model 2). In this quadratic function, ERs is incorporated as a linear term as well as a quadratic term. The linear term of ERs can be treated as the predictor in the link between ERs and EP, whereas the quadratic term of ERs can be regarded as the moderator (Pierce and Aguinis, 2011). To avoid the potential multi-collinearity problem caused by the quadratic term, ERs 
are centered before adding into the model (Aiken and West, 1991).

$$
\begin{aligned}
& \mathrm{EP}_{i t}=\mathrm{C}+\beta_{1} E R s_{i t}+\beta_{2} E R s_{i t}^{2}+\beta_{3} P_{e r} G D P_{i t}+\beta_{4} F D I_{i t}+\beta_{5} E_{n e r g y} y_{i t}+\beta_{6} R \& D_{i t} \\
& +\beta_{7} \text { Scale }_{i t}+\epsilon_{i t} \quad \text { Model } 2
\end{aligned}
$$

Table 4 presents the results of descriptive statistics of all variables. We further provide the results of the test for equality of mean and median difference of main variables between two different regions in Table 5. Seeing at the last two columns, both the mean and median value of the variables between two regions are significantly different as T-test value and Chi-square are all significant at $1 \%$ level. They can give support that different regions implement ERs differently. Besides, the results also demonstrate that EP and economic development level in Eastern regions are much higher than in Inland regions as the mean value of EP and Per_GDP are much higher. Correlation coefficients of variables are available in Table 6.

Table 4 Descriptive statistics of all variables included in this paper

\begin{tabular}{lcccc}
\hline Variable & Mean & S.D. & Min & Max \\
\hline EP & 0.781 & 0.250 & 0.192 & 1.473 \\
CMCER & 7.325 & 1.385 & 2.079 & 10.56 \\
MBER & 8.601 & 5.947 & 0.440 & 46.79 \\
INFER & 9.540 & 1.406 & 3.912 & 12.27 \\
Per_GDP & 3.135 & 2.049 & 0.432 & 10.52 \\
FDI & 0.056 & 0.074 & 0.007 & 0.750 \\
Energy & 1.201 & 0.659 & 0.320 & 4.323 \\
R\&D & 0.023 & 0.026 & 0.003 & 0.172 \\
Scale & 2.436 & 1.592 & 0.407 & 8.739
\end{tabular}

\begin{tabular}{|c|c|c|c|c|c|c|c|c|}
\hline \multirow{2}{*}{ Variables } & \multicolumn{3}{|c|}{ Eastern regions } & \multicolumn{3}{|c|}{ Inland regions } & \multirow{2}{*}{ T-test } & \multirow{2}{*}{ Chi-square } \\
\hline & Obs. & Mean & Median & Obs. & Mean & Median & & \\
\hline EP & 121 & 0.961 & 0.984 & 209 & 0.677 & 0.673 & $11.882^{* * *}$ & $65.781^{* \star *}$ \\
\hline CMCER & 121 & 7.98 & 8.518 & 209 & 6.946 & 7.14 & $6.990^{* * *}$ & $39.474^{\star * \star}$ \\
\hline MBER & 121 & 5.527 & 4.634 & 209 & 10.38 & 8.709 & $-7.758^{* * *}$ & $24.128^{* * *}$ \\
\hline INFER & 121 & 10.1 & 10.263 & 209 & 9.216 & 9.449 & $5.769^{* \star *}$ & $42.397^{* * *}$ \\
\hline Per_GDP & 121 & 4.608 & 4.111 & 209 & 2.281 & 2.005 & $11.872^{* * *}$ & $51.792^{\star * \star}$ \\
\hline
\end{tabular}

Table 5 Test for equality of mean and median difference of main variables between two regions

$* p<0.1 ; * * p<0.05 ; * * * p<0.01$.

\begin{tabular}{|c|c|c|c|c|c|c|c|c|c|}
\hline & $\mathrm{EP}$ & CMCER & MBER & INFER & Per_GDP & FDI & Energy & R\&D & Scal \\
\hline $\mathrm{EP}$ & 1 & & & & & & & & \\
\hline CMCER & $0.241 * * *$ & 1 & & & & & & & \\
\hline MBER & $-0.491 * *$ & 0.023 & 1 & & & & & & \\
\hline INFER & $0.269 * * *$ & $0.515 * * *$ & $-0.371 * *$ & 1 & & & & & \\
\hline Per_GD & $0.404 * * *$ & $0.237 * * *$ & $-0.525 * *$ & $0.438 * * *$ & 1 & & & & \\
\hline
\end{tabular}

Table 6 Correlation coefficients of all variables 
An earlier version of the paper accepted for publication in Journal of Cleaner Production, June 2018

\begin{tabular}{cccccccccc}
\hline FDI & $0.374 * * *$ & -0.076 & $-0.269 * *$ & -0.002 & $0.272 * * *$ & 1 & & & \\
Energy & $-0.454 * *$ & $-0.319 * *$ & $0.644 * * *$ & $-0.552 * *$ & $-0.553 * *$ & $-0.278 * *$ & 1 & & \\
R\&D & $0.324 * * *$ & $0.227 * * *$ & $-0.310 * *$ & $0.247 * * *$ & $0.507 * * *$ & $0.111 * *$ & $-0.381 * *$ & 1 & \\
Scale & $0.528 * * *$ & 0.065 & $-0.492 * *$ & $0.193 * * *$ & $0.669 * * *$ & $0.308 * * *$ & $-0.324 * *$ & $0.390 * *$ & 1 \\
\hline
\end{tabular}

$* \mathrm{p}<0.1 ; * * \mathrm{p}<0.05 ; * * * \mathrm{p}<0.01$.

4. Results and discussions

4. 1 Regression rResults of the link between command-and-control ERs and EP Table 7 presents the regression results of the link between CMCER and EP. For the whole of China, the direct link between CMCER and EP is negative but not significant ( $a=-0.0083, p=$ n. s. ). Hence, H1a is not supported. But the non-1inear regression results show contrasting results. The coefficient of the linear term of CMCER is significantly negative $(\beta=-0.1064, p<0.1)$, and the coefficient of the quadratic term of CMCER is significantly positive $(\beta=0.0069, p<0.1)$ for the whole of China. The results provide support for the non-linear relationship between CMCER and EP in China. Thus, H2a is supported. We further analyze the variation of the relationship between ERs and EP across two regions. For Eastern regions, both the significance of the linear term of CMCER in Model 1 and the significance of the quadratic term of CMCER in Model 2 are insignificant. For Inland regions, the results are almost consistent with Eastern regions. Both the significance of the direct link and the non-linear link between CMCER and EP are insignificant. Hence, the results do not support H3a as the link between CMCER and EP are both neutral in Eastern and Inland regions.

\subsection{Results Regression results of the link between market-based ERs and EP}

The regression results of the link between MBER and EP are presented in Table 8. For the whole of China, the direct link between MBER and EP is negative and significant $(\alpha=-0.0130, p<0.01)$. The non-linear regression results show that the coefficient of the linear term of MBER is negative $(\beta=-0.0286, p<0.01)$, and the coefficient of the quadratic term of MBER is positive and significant $(\beta=0.0004$, $p<0.01)$. However, the $\mathrm{F}-$ statistic and adjusted $-\mathrm{R}^{2}$ of Model 2 are much higher than that of Model 1, it can be concluded that there is evidence for a non-linear relationship between MBER and EP in China. Thus, H1b is not supported, but H2b is supported. For Eastern regions, only the coefficient of MBER in Model 1 is 
significantly negative ( $\alpha=-0.0257, p<0.01)$. It can support that there is a negative link between MBER and EP in Eastern regions. For Inland regions, the direct link between MBER and EP is significant and negative $(\alpha=-0.0118, p<0.01)$. With regard to the non-linear link, the coefficient of the linear term is significantly negative ( $\beta=-0.0291, p<0.01)$, whereas the coefficient of the quadratic term is significantly positive $(\beta=0.0004, \quad p<0.01)$. But we can conclude that there is a non-linear relationship between MBER and EP in Inland regions as F-statistic and adjusted-R are much higher. Overal1, the link between MBER and EP is negative in Eastern regions but non-linear in Inland regions, which provides support for H3b.

4. 3 Results Regression results of the link between informal regulations and EP Relevant regression results of the link between INFER and EP are available in Table 9. The empirical results for the whole of China, Eastern regions and Inland regions are quite similar. In Model 1, the coefficient of INFER is insignificant. In Model 2 , both the coefficient of the linear term and the coefficient of the quadratic term are insignificant as well. All these results indicate that the link between INFER and EP is neutral whichever for the whole of China, Eastern regions or Inland regions. Thus, our H1c, H2c and H3c are all not supported. 


\begin{tabular}{lllllll}
\hline \multirow{2}{*}{ Table 7 Regression results of the link between CMCER and EP (Dependent variable: EP) } \\
\cline { 2 - 6 } Variables & \multicolumn{5}{c}{ Model 1} \\
\cline { 2 - 7 } & The whole of China & Eastern & Inland & The whole of China & Eastern & Inland \\
\hline C & $0.8121 * * *$ & $1.0040 * * *$ & $0.6306 * * *$ & $1.1689 * * *$ & $1.4661 * * *$ & $0.9562 * * *$ \\
CMCER & -0.0083 & 0.0070 & -0.0176 & $-0.1064 *$ & -0.1124 & -0.1088 \\
CMCER^2 & & & & $0.0069 *$ & 0.0082 & 0.0065 \\
Per_GDP & $0.0276 * *$ & 0.0103 & $0.0525 * * *$ & $0.0280 * *$ & 0.0074 & $0.0544 * * *$ \\
FDI & -0.0747 & -0.0910 & 1.3101 & -0.1161 & -0.1464 & 1.3341 \\
Energy & $0.0758 * *$ & 0.0175 & $0.1041 * *$ & $0.0693 * *$ & -0.0084 & $0.1001 * *$ \\
R\&D & $-13.5488 * * *$ & $-10.7654 * * *$ & $-17.0411 * * *$ & $-13.8825 * * *$ & $-10.9919 * * *$ & $-17.3651 * * *$ \\
Scale & $0.0702 * * *$ & $0.0650 * * *$ & $0.0824 * * *$ & $0.0675 * * *$ & $0.0634 * * *$ & $0.0785 * * *$ \\
Obs. & 330 & 121 & 209 & 330 & 121 & 209 \\
$\mathrm{R}^{2}$ & 0.2543 & 0.2420 & 0.2918 & 0.2615 & 0.2497 & 0.2992 \\
Adj-R ${ }^{2}$ & 0.165 & 0.125 & 0.199 & 0.171 & 0.126 & 0.203 \\
F & 16.71 & 5.533 & 12.64 & 14.82 & 4.897 & 11.16 \\
\hline
\end{tabular}

$* \mathrm{p}<0.1 ; * * \mathrm{p}<0.05 ; * * * \mathrm{p}<0.01$ 


\begin{tabular}{lllllll}
\hline \multirow{2}{*}{ Table 8 Regression results of the link between MBER and EP (Dependent variable: EP) } \\
\hline \multirow{5}{*}{ Variables } & \multicolumn{5}{c}{ Model 1} \\
\cline { 2 - 7 } & \multicolumn{7}{c}{ The whole of China } & Eastern & Inland & \multicolumn{4}{c}{ The whole of China } & Eastern & Inland \\
\hline C & $0.7887 * * *$ & $1.1551 * * *$ & $0.5813 * * *$ & $0.9245 * * *$ & $0.9874 * * *$ & $0.7602 * * *$ \\
MBER & $-0.0130 * * *$ & $-0.0257 * * *$ & $-0.0118 * * *$ & $-0.0286 * * *$ & -0.0026 & $-0.0291 * * *$ \\
MBER^2 & & & & $0.0004 * * *$ & -0.0013 & $0.0004 * * *$ \\
Per_GDP & $0.0218 *$ & -0.0160 & $0.0468 * * *$ & 0.0092 & -0.0124 & $0.0320 *$ \\
FDI & -0.0908 & -0.0967 & -0.1586 & -0.0903 & -0.1119 & -0.3984 \\
Energy & $0.1505 * * *$ & 0.0969 & $0.1824 * * *$ & $0.1439 * * *$ & 0.1271 & $0.1793 * * *$ \\
R\&D & $-12.5671 * * *$ & $-7.0952 * *$ & $-16.2146 * * *$ & $-11.8567 * * *$ & $-6.4175 *$ & $-16.0509 * * *$ \\
Scale & $0.0624 * * *$ & $0.0583 * * *$ & $0.0693 * * *$ & $0.0568 * * *$ & $0.0688 * * *$ & $0.0605 * * *$ \\
Obs. & 330 & 121 & 209 & 330 & 121 & 209 \\
$\mathrm{R}^{2}$ & 0.3024 & 0.2938 & 0.3415 & 0.3230 & 0.3005 & 0.3726 \\
Adj-R $\mathbf{R}^{2}$ & 0.219 & 0.185 & 0.256 & 0.240 & 0.185 & 0.287 \\
$\mathrm{~F}$ & 23.61 & 7.38 & 17.17 & 23.82 & 7.01 & 17.56 \\
\hline
\end{tabular}

$* \mathrm{p}<0.1 ; * * \mathrm{p}<0.05 ; * * * \mathrm{p}<0.01$. 
Table 9 Regression results of the link between INFER and EP (Dependent variable: EP)

\begin{tabular}{lllllll}
\hline \multirow{2}{*}{ Variables } & \multicolumn{3}{c}{ Model 1 } & \multicolumn{3}{c}{ Model 2 } \\
\cline { 2 - 7 } & The whole of China & Eastern & Inland & The whole of China & Eastern & Inland \\
\hline C & $0.7669 * * *$ & $1.0181 * * *$ & $0.5553 * * *$ & $0.9785 * * *$ & 1.0759 & $0.8324 * * *$ \\
INFER & -0.0013 & 0.0034 & -0.0056 & -0.0525 & -0.0087 & -0.0752 \\
INFER^2 & & & & 0.0032 & 0.0006 & 0.0045 \\
Per_GDP & $0.0271 * *$ & 0.0097 & $0.0498 * * *$ & $0.0245 *$ & 0.0094 & $0.0448 * *$ \\
FDI & -0.0688 & -0.0867 & 1.6561 & -0.0953 & -0.0976 & 1.6624 \\
Energy & $0.0737 * *$ & 0.0215 & $0.0948 * *$ & $0.0714 * *$ & 0.0214 & $0.0895 * *$ \\
R\&D & $-13.4819 * * *$ & $-10.6506 * * *$ & $-16.2788 * * *$ & $-13.7157 * * *$ & $-10.6759 * * *$ & $-17.0074 * * *$ \\
Scale & $0.0698 * * *$ & $0.0657 * * *$ & $0.0833 * * *$ & $0.0701 * * *$ & $0.0657 * * *$ & $0.0836 * * *$ \\
Obs. & 330 & 121 & 209 & 330 & 121 & 209 \\
$\mathrm{R}^{2}$ & 0.2533 & 0.2417 & 0.2875 & 0.2559 & 0.2417 & 0.2935 \\
Adj-R $\mathbf{R}^{2}$ & 0.164 & 0.125 & 0.195 & 0.164 & 0.117 & 0.197 \\
F & 16.62 & 5.524 & 12.37 & 14.40 & 4.691 & 10.86 \\
\hline
\end{tabular}

$* \mathrm{p}<0.1 ; * * \mathrm{p}<0.05 ; * * * \mathrm{p}<0.01$. 


\section{4 Discussions}

Our empirical results highlight that there is no evidence of a positive link between CMCER and EP, and INFER and EP in the Chinese context. In contrast, MBER has a significant but negative relationship with EP in Eastern regions. However, our hypotheses on the non-linear links are better supported in the case of CMCER and MBER. There is evidence that the link between CMCER and ER and the link between MBER and EP are non-linear for the whole of China. In the case of MBER, this non-1inear link is supported for Inland regions as well. However, there is no evidence of either direct or non-linear link between INFER and EP.

Our hypotheses on the variation of the ERs-EP links across different regions are partially supported. The link between MBER and EP varies across different regions, whereas the link between CMCER and EP and the link between INFER and EP do not vary across different regions.

In the case of CMCER, the results show that the non-linear relationship for the whole of china and the neutral links for Eastern and Inland regions. The non-linear relationship is somewhat supported by the findings of Xie et al. (2017). They show a similar non-linear relationship between CMCER and "green” productivity. Undesirable outputs (i. e. C02 emissions) are considered, when evaluating “green” productivity. The possible reason for the neutral links may lie in the intensity of mandatory regulations in Eastern and Inland regions is not enough to have positive impacts on firms' behavior to improve EP, although the intensity of mandatory regulations has been increasing (Lin et al., 2015; Zhao et al., 2015b).

In the case of MBER, we have evidence of a significant (but negative) direct relationship as well as significant non-linear relationship between MBER and EP. Though the direct link is contrary to our hypotheses (that hypothesized significant positive direct relationship), the positive links are indirectly supported by the positive non-linear link. The positive non-linear link provides evidence for a “turning point” where the link becomes from being negative to positive. This is sketched in Figure 1. Since the quadratic term for the whole of China, and for inland region is positive, the negative relationship can become less negative as the intensity of MBER increases. When the intensity of MBER surpasses the turning point, MBER can have their positive impacts on EP. Xie et al. (2017) also show a non-linear relationship between MBER and “green” productivity. 


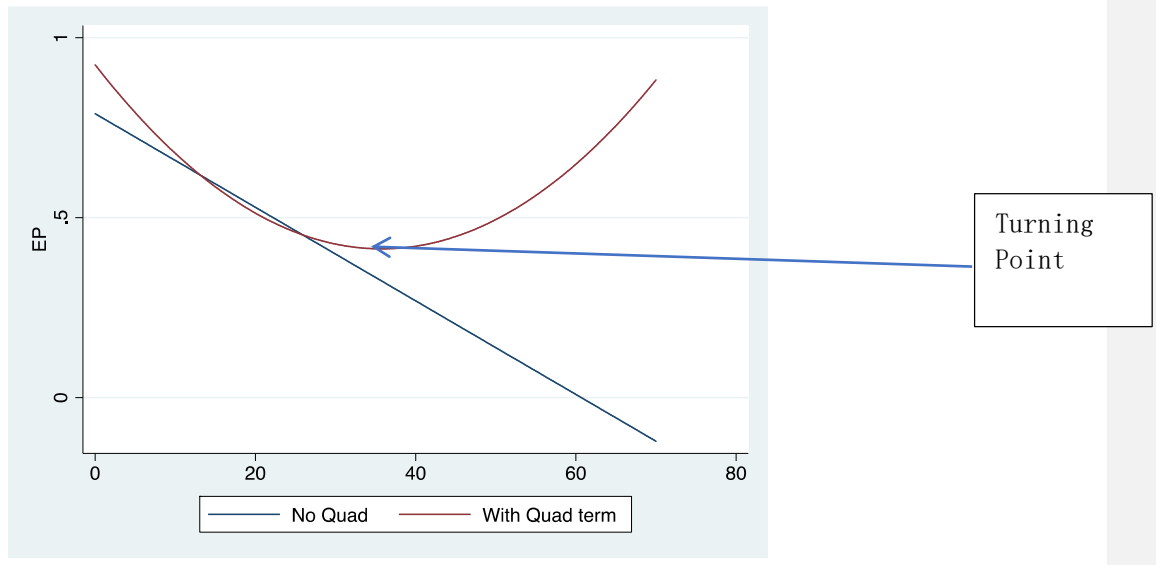

Figure 1| A sketch of the direct and non-linear relationships between MBER and EP for the whole of China

In the case of INFER, there are evidences of the neutral links for the whole of China, Eastern regions and Inland regions. These results of the neutral links are also in line with some prior studies (e. g. Blackman and Kildegaard, 2010; Cole et al. , 2008; Pargal et al., 1997). One of the possible reasons is that public involvement in environmental issues is still limited and public environmental awareness is still weak in China (Liu et al., 2010; Zheng and Shi, 2017). Another reason maycould be that local governments may not exert enough pressures on firms or take proper measures to address these environmental complaints, when receiving public complaints from citizens. The failure to address public complaints cannot transform these pressures into the driving force to further affect firms' behavior. Taken together, INFER now still cannot exert strong enough pressures on affecting firms' behavior significantly. Thus, the link between INFER and EP is likely to be neutral. Our results highlight the non-linear link between CMCER and EP for the whole of China, and the non-linear link between MBER and EP for the whole of China and Inland regions. These results provide deeper insights for understanding IT and ST. IT and ST do support the positive impacts of institutional pressures or stakeholder pressures on encouraging firms to engage more in environmental initiatives, but the pressures can exert their positive impacts only after arriving at the certain level. Our results also show the link between CMCER and EP do not vary across different regions as well as the link between INFER and EP, but the link between MBER and EP varies across different regions. The variation of the link between MBER and EP across
Commented [RR1]: Remove the Axis labels. Do not have $0,0.5,20,40$, etc. 
different regions support that the significant difference in economic development level between Eastern and Inland regions can lead local governments to implement ERs differently (see Table 5). Hence, ERs in different regions can exert different levels of pressures on affecting firms' behavior and further shape the link between ERs and EP differently. Nevertheless, when the pressures that ERs exert in different regions are not strong enough to affect firms' environmental practice significantly, ERs cannot have significant impacts on EP and the link between ERs and EP is likely to keep neutral still. Hence, the link between ERs and EP may not vary across different regions.

It is worth highlighting here that Tables 7-9 show that the links between Per GDP and EP are significantly positive for the whole of China and Inland regions but not for Eastern regions. This shows strong link between economic prosperity and the ERs-EP link. However, the nature impacts of economic development level on EP may be more complex in the Chinese context, since the better achievement in Per_GDP (Eastern regions) does not accompany a better EP, but Per_GDP can have positive impact on EP in less developed regions (Inland regions). Hence, the link between Per_GDP and EP may have been shaped differently in Chinal.

\section{Conclusions}

In this paper, we use the literature to differentiate three types of ERs and investigate the nature of the links between different types of ERs and EP. Building our research upon IT and ST, we investigate both the positive relationships and the potential non-linear relationships, and further investigate whether the specific ERs-EP link varies across different regions of China (Eastern and Inland). In doing so, we collect the required data from different China statistical yearbooks. 30 provinces are included finally and the time periods cover from 2004 to 2014. Our results indicate that, for the link between CMCER and EP, there is a non-linear relationship for the whole of China, whereas a neutral link has been found both in Eastern and Inland regions. Hence, the link between CMCER and EP does not vary across different regions. With respect to the link between MBER and EP, a non-linear relationship has been found for the whole of China and Inland regions, but a negative relationship has been found for Eastern regions. Hence, the variation of the link between MBER and EP across different regions has been verified. The link between INFER and EP shows different results. They are all neutral for the whole of China, 
Eastern regions and Inland regions. Thus, the link between INFER and EP does not vary across different regions as well.

Drawing on our findings, some significant implications can be derived. Firstly, since the negative and the neutral links have been found, to realize the positive impacts of ERs on EP, the central government should continue to improve the intensity of ERs, especially properly and strictly designed ERs are needed. Moreover, a new evaluation system for promoting local officials may be needed to guarantee and encourage ERs can be implemented strictly (Zheng and Shi, 2017). If ERs cannot be strictly implemented, they will exert no pressure on affecting firms' behavior (Tang et al., 2003). The new evaluation system should encourage local officials to focus on developing economy as well as protecting the environment and prevent the development of economy from sacrificing the environment. Secondly, the government should encourage and provide more channels for stakeholders (i.e. citizens, communities) to engage more in environmental issues. At the same time, the government should also treat public complaints on environmental issues seriously so that it can provide further incentives for citizens to participate in environmental issues. Thirdly, the government should provide more different types of properly designed instruments. Currently, CMCER still dominate Chinese environmental policies (Xie et al., 2017; Zhao et al., 2015b). Apart from the mandatory instruments, economic instruments and other types of instruments are also needed. A good combination of all kinds of instruments can be helpful as suggested by Iraldo et al. (2011) that the key question is not “which instrument is best”, but “which mix of instruments is best". Thus, local governments have more choices on adopting different instruments to regulate firms' behavior.

Our research has made several contributions to the literature. Firstly, this research provides empirical evidence for the impacts of ERs on EP from an emerging country. Secondly, this paper extends the literature by differentiating three different types of ERs and investigate the nature of the links between different types of ERs and EP. Thirdly, this paper enhances previous studies by investigating the potential non-linear relationship between ERs and EP. To the best of our knowledge, it is the first paper to investigate the non-linear links between different types of ERs and EP.

Despite the contributions, our paper also has some limitations. Firstly, due to the limitation of data, we only use the number of complaint letters on environmental 
issues to capture INFER. However, INFER may also consist of consumers, environmental NG0s, media pressures and so on (Zhang et al., 2008). Future study can collect more data and create a comprehensive index to capture INFER, then investigate whether INFER have non-1inear impacts on EP. Furthermore, our research only focusses on the Chinese context. China is still a big developing country and its environmental governance system may have its own characteristics. Future study may collect more data from different countries to check whether the conclusions we obtained in this paper are robust or not.

\section{References:}

Aden, J., Kyu-Hong, A., Rock, M. T., 1999. What is driving the pollution abatement expenditure behavior of manufacturing plants in Korea? World Dev. 27, $1203-1214$. doi :10. 1016/S0305-750X (99) 00046-7

Agan, Y., Acar, M.F., Borodin, A., 2013. Drivers of environmental processes and their impact on performance: A study of Turkish SMEs. J. Clean. Prod. 51, $23-33$. doi:10. 1016/j. jclepro. 2012. 12.043

Aguilera-caracuel, J., Ortiz-de-Mandojana, N., 2013. Green innovation and financial performance: An institutional approach. Organ. Environ. 26, $365-385$. doi : 10. 1177/1086026613507931

Aiken, L. S., West, S.G., 1991. Multiple regression: Testing and interpretation interactions. SAGE Publications.

Bansal, P., 2005. Evolving sustainably: A longitudinal study of corporate sustainable development. Strateg. Manag. J. 26, $197-218$. doi:10. 1002/smj. 441

Baylis, R., Connell, L., Flynn, A., 1998. Company size, environmental regulation and ecological modernization: Further analysis at the level of the firm. Bus. Strateg. Environ. 7, $285-296$.

Bi, G., Luo, Y., Ding, J., Liang, L., 2015. Environmental performance analysis of Chinese industry from a slacks-based perspective. Ann. Oper. Res. 228, $65-80$. doi:10. 1007/s10479-012-1088-3

Bian, Y., Liang, N., Xu, H., 2015. Efficiency evaluation of Chinese regional industrial systems with undesirable factors using a two-stage slacks-based measure approach J. Clean. Prod. 87, 348 - 356. doi:10. 1016/j. jclepro. 2014. 10. 055

Blackman, A., 2010. Alternative pollution control policies in developing countries. Rev. Environ. Econ. Policy 4, $234-253$. doi:10. 1093/reep/req005

Blackman, A., Kildegaard, A., 2010. Clean technological change in developing-country industrial clusters: Mexican leather tanning. Environ. Econ. Policy Stud. 12, 115 132. doi:10. 1007/s10018-010-0164-7

Blohmke, J., Kemp, R., Türkeli, S., 2016. Disentangling the causal structure behind environmental regulation. Technol. Forecast. Soc. Change 103, 174-190. doi:10. 1016/ j. techfore. 2015. 10. 013

Böhringer, C., Moslener, U., Oberndorfer, U., Ziegler, A., 2012. Clean and productive? Empirical evidence from the German manufacturing industry. Res. Policy 41, $442-$ 451. doi:10. 1016/j. respol. 2011. 10. 004

Brammer, S., Hoejmose, S., Marchant, K., 2012. Environmental management in SMEs in the UK: Practices, pressures and perceived benefits. Bus. Strateg. Environ. 21, $423-$ 434. doi:10. 1002/bse. 717

Camisón, C., 2010. Effects of coercive regulation versus voluntary and cooperative auto-regulation on environmental adaptation and performance: Empirical evidence in Spain. Eur. Manag. J. 28, 346 - 361. doi:10. 1016/j. emj. 2010. 03. 001

Clarkson, P.M., Li, Y., Richardson, G. D., Vasvari, F. P., 2008. Revisiting the relation between environmental performance and environmental disclosure: An empirical 
analysis. Accounting, Organ. Soc. 33, $303-327$. doi:10. 1016/j. aos. 2007. 05. 003

Cole, M. A., Elliott, R. J.R., Shimamoto, K., 2005. Industrial characteristics, environmental regulations and air pollution: An analysis of the UK manufacturing sector. J. Environ. Econ. Manage. 50, 121 - 143. doi:10. 1016/ j. jeem. 2004. 08. 001

Cole, M. A., Elliott, R. J.R., Wu, S., 2008. Industrial activity and the environment in China: An industry-1evel analysis. China Econ. Rev. 19, $393-408$. doi:10. 1016/j. chieco. 2007. 10. 003

Cordeiro, J. J., Sarkis, J., 1997. Environmental proactivism and firm performance: Evidence from security analyst earnings forecasts. Bus. Strateg. Environ. 6, $104-$ 114. doi:10. 1002/(SICI) 1099-0836(199705) 6:2<104::AID-BSE102〉3. 0. C0;2-T

Dasgupta, S., Laplante, B., Mamingi, N., Wang, H., 2001. Inspections, pollution prices, and environmental performance: Evidence from China. Ecol. Econ. 36, $487-498$. doi : 10. 1016/S0921-8009 (00) 00249-4

De Brito, M. P., Carbone, V., Blanquart, C. M. , 2008. Towards a sustainable fashion retail supply chain in Europe: Organisation and performance. Int. J. Prod. Econ. 114, 534 553. doi:10. 1016/j. i jpe. 2007.06. 012

Delmas, M. A., Nairn-Birch, N., Lim, J., 2015. Dynamics of environmental and financial performance: The case of greenhouse gas emissions. Organ. Environ. 28, $374-393$. doi: $10.1177 / 1086026615620238$

Delmas, M.A., Toffel, M.W., 2008. Organizational responses to environmental demands: Opening the black box. Strateg. Manag. Journa 29, $1027-1055$. doi:10. 1002/smj

Dimaggio, P. J., Powel1, W.W., 1983. The iron cage revisited: Institutional isomorphism and collective rationality in organizational fields. Am. Sociol. Rev. 48, 147 160. doi:10. 2307/2095101

Eiadat, Y., Kelly, A., Roche, F., Eyadat, H., 2008. Green and competitive? An empirical test of the mediating role of environmental innovation strategy. J. World Bus. 43, 131 - 145. doi:10.1016/j. jwb. 2007.11. 012

Esty, D. C., Porter, M.E., 2002. Ranking national environmental regulation and performance: A leading indicator of future competitiveness? Glob. Compet. Rep. 78 100. doi:http://dx. doi. org/10.1017/S1355770X05002275

Féres, J., Reynaud, A., 2012. Assessing the impact of formal and informal regulations on environmental and economic performance of Brazilian manufacturing firms. Environ. Resour. Econ. 52, 65 - 85. doi:10. 1007/s10640-011-9520-8

Francesch-Huidobro, M. , Lo, C.W. H. , Tang, S. Y., 2012. The local environmental regulatory regime in China: Changes in pro-environment orientation, institutional capacity, and external political support in Guangzhou. Environ. Plan. A 44, $2493-2511$. doi: 10. 1068/a44504

Fujii, H., Iwata, K., Kaneko, S., Managi, S., 2013. Corporate environmental and economic performance of Japanese manufacturing firms: Empirical study for sustainable development. Bus. Strateg. Environ. 22, 187 -201. doi:10. 1002/bse. 1747

Gouldson, A., Carpenter, A., Afionis, S., 2014. An international comparison of the outcomes of environmental regulation. Environ. Res. Lett. 9, $1-9$. doi : 10. 1088/1748-9326/9/7/074019

Graafland, J., Smid, H., 2017. Reconsidering the relevance of social license pressure and government regulation for environmental performance of European SMEs. J. Clean. Prod. 141, 967 - 977. doi:10. 1016/j. jclepro. 2016. 09. 171

Graves, S. B., Waddock, S. A., 1999. A look at the financial-social performance nexus when quality of management is held constant. Int. J. Value-Based Manag. 12, $87-99$.

Griffin, J. J., Mahon, J.F., 1997. The corporate social performance and corporate financial performance debate: Twenty-five years of incomparable research. Bus. Soc. 36, 5-31. doi:0803973233

Guo, L., Qu, Y., Tseng, M., 2017. The interaction effects of environmental regulation and technological innovation on regional green growth performance. J. Clean. Prod. doi:10.1016/j. jclepro. 2017.05. 210

Halkos, G., Sepetis, A., 2007. Can capital markets respond to environmental policy of firms? Evidence from Greece. Ecol. Econ. 63, 578 - 587. doi : 10. 1016/j. ecolecon. 2006. 12. 015

Hamamoto, M., 2006. Environmental regulation and the productivity of Japanese 
manufacturing industries. Resour. Energy Econ. 28, $299-312$.

doi:10. 1016/j. reseneeco. 2005. 11. 001

Henriques, I., Sadorsky, P., 1996. The determinants of an environmentally responsive firm: An empirical approach. J. Environ. Econ. Manage. 30, $381-395$. doi:10. 1006/jeem. 1996. 0026

Horbach, J., Rammer, C., Rennings, K., 2012. Determinants of eco-innovations by type of environmental impact - The role of regulatory push/pull, technology push and market pull. Ecol. Econ. 78, 112 - 122. doi:10. 1016/j. ecolecon. 2012. 04.005

Horváthová, E., 2012. The impact of environmental performance on firm performance: Short-term costs and long-term benefits? Ecol. Econ. 84, $91-97$. doi: 10. 1016/j. ecolecon. 2012. 10. 001

Horváthová, E., 2010. Does environmental performance affect financial performance? A meta-analysis. Ecol. Econ. 70, 52 - 59. doi:10. 1016/j. ecolecon. 2010. 04.004

Hu, D., Wang, Y., Huang, J., Huang, H., 2017. How do different innovation forms mediate the relationship between environmental regulation and performance? J. Clean. Prod. 161, 466 - 476. doi:10. 1016/j. jclepro. 2017. 05. 152

Hu, J. L., Wang, S. C., 2006. Total-factor energy efficiency of regions in China. Energy Policy 34, 3206 - 3217. doi:10. 1016/j. enpol. 2007.10. 026

Iraldo, F., Testa, F., Frey, M., 2009. Is an environmental management system able to influence environmental and??competitive performance? The case of the eco-management and audit scheme (EMAS) in the European union. J. Clean. Prod. 17, 1444 - 1452. doi:10. 1016/j. jclepro. 2009. 05. 013

Iraldo, F., Testa, F., Melis, M. , Frey, M. , 2011. A literature review on the links between environmental regulation and competitiveness. Environ. Policy Gov. 21, $210-222$. doi:10. 1002/eet. 568

Iwata, H. , Okada, K., 2011. How does environmental performance affect financial performance? Evidence from Japanese manufacturing firms. Ecol. Econ. 70, 1691 1700. doi:10. 1016/j. ecolecon. 2011. 05. 010

Jacobs, B.W., Singhal, V.R., Subramanian, R., 2010. An empirical investigation of environmental performance and the market value of the firm. J. Oper. Manag. 28, 430 - 441. doi:10. 1016/j. jom. 2010. 01.001

Jaffe, A. B., Newe11, R. G., Stavins, R. N., 2002. Environmental policy and technological change. Environ. Resour. Econ. 22, $41-69$.

Jaffe, A. B., Palmer, K., 1997. Environmental regulation and innovation: A panel data study. Rev. Econ. Stat. 79, $610-619$.

Jiménez, 0., 2005. Innovation-oriented environmental regulations: Direct versus indirect regulations; An empirical analysis of small and medium-sized enterprises in Chile. Environ. Plan. A 37, 723 - 750. doi:10. 1068/a3736

Kagan, R. A., Gunningham, N., Thornton, D., 2003. Explaining corporate environmental performance: How does regulation matter? Law Soc. Rev. 37, $51-90+1$. doi:10. 1111/1540-5893. 3701002

Kassinis, G., Vafeas, N., 2006. Stakeholder pressures and environmental performance. Acad. Manag. J. 49, 145 - 159. doi:10. 5465/AMJ. 2006. 20785799

Khanna, M., 2001. Non-mandatory approaches to environmental protection. J. Econ. Surv. $15,291-324$.

Kneller, R., Manderson, E., 2012. Environmental regulations and innovation activity in UK manufacturing industries. Resour. Energy Econ. 34, $211-235$. doi:10. 1016/j. reseneeco. 2011. 12. 001

Lin, H., Zeng, S., Ma, H., Chen, H., 2015. Does commitment to environmental self-regulation matter? An empirical examination from China. Manag. Decis. 53, 932 - 956. doi:10. 1108/MD-07-2014-0441

Liu, B., Yu, Q., Zhang, B., Bi, J., Ge, J., Yuan, Z., Yu, Y., 2010. Does the GreenWatch program work? Evidence from a developed area in China. J. Clean. Prod. 18, 454 461. doi:10. 1016/j. jclepro. 2009. 11.012

Liu, X., Liu, B., Shishime, T., Yu, Q., Bi, J., Fujitsuka, T., 2010. An empirical study on the driving mechanism of proactive corporate environmental management in China. J. Environ. Manage. 91, 1707 - 17. doi:10. 1016/j. jenvman. 2010. 03. 011

Lo, C.W. -H. , Fryxe11, G. E., Van Rooij, B., 2009. Changes in enforcement styles among 
environmental enforcement officials in China. Environ. Plan. A 41, $2706-2723$. doi: 10. 1068/a41357

Majumdar, S. K., Marcus, A.A., 2001. Rules versus discretion: The productivity consequences of flexible regulation. Acad. Manag. J. 44, $170-179$. doi : 10. 2307/3069344

Mendes, L.M. Z., Santos, G., 2008. Using economic instruments to address emissions from air transport in the European Union. Environ. Plan. A 40, $189-209$. doi:10. 1068/a39255md

Muhammad, N., Scrimgeour, F., Reddy, K., Abidin, S., 2015. The relationship between environmental performance and financial performance in periods of growth and contraction: Evidence from Australian publicly listed companies. J. Clean. Prod. 102, 1 - 9. doi:10. 1016/j. jclepro. 2015.04. 039

Nakao, Y., Amano, A., Matsumura, K., Genba, K., Nakano, M., 2007a. Relationship between environmental performance and financial performance: An empirical analysis of Japanese corporations. Bus. Strateg. Environ. 16, 106 -118. doi:10. 1002/bse. 476

Nakao, Y., Nakano, M., Amano, A., Kokubu, K., Matsumura, K., Gemba, K., 2007b. Corporate environmental and financial performances and the effects of information-based instruments of environmental policy in Japan. Int. J. Environ. Sustain. Dev. 6, 95 - 112. doi:10. 1504/IJESD. 2007. 012739

Pargal, S., Mani, M., Huq, M., 1997. Inspections and emissions: Puzzling survey evidence on industrial water pollution, PRD working paper. World Bank Publications.

Pargal, S., Wheeler, D., 1996. Informal regulation of industrial pollution in developing countries: Evidence from Indonesia. J. Polit. Econ. 104, $1314-1327$.

Phan, T. N., Baird, K., 2015. The comprehensiveness of environmental management systems: The influence of institutional pressures and the impact on environmental performance. J. Environ. Manage. 160, 45 - 56. doi:10. 1016/j. jenvman. 2015. 06. 006

Picazo-Tadeo, A. J., García-Reche, A., 2007. What makes environmental performance differ between firms? Empirical evidence from the Spanish tile industry. Environ. Plan. A 39, 2232 - 2247. doi:10. 1068/a38223

Pierce, J.R., Aguinis, H., 2011. The too-much-of-a-good-thing effect in management. J. Manage. 39, 313-338. doi:10. 1177/0149206311410060

Qi, G. Y., Zeng, S. X., Shi, J. J., Meng, X. H. , Lin, H., Yang, Q. X. , 2014. Revisiting the relationship between environmental and financial performance in Chinese industry. J. Environ. Manage. 145, 349 - 356. doi:10. 1016/j. jenvman. 2014. 07. 010

Ramanathan, R., 2016. Understanding complexity: The curvilinear relationship between environmental performance and firm performance. J. Bus. Ethics $1-11$. doi:10. 1007/s10551-016-3088-8

Ramanathan, R., Akanni, A. 0., 0luwatomi, A., 2015. The moderating effect of operations efficiency on the links between environmental performance and financial performance: The UK evidence. Asian J. Innov. Policy 4, 76-102.

Ramanathan, R., Poomkaew, B., Nath, P., 2014. The impact of organizational pressures on environmental performance of firms. Bus. Ethics A Eur. Rev. 23, $169-182$. doi: 10.1111 /beer. 12042

Ramanathan, R., Ramanathan, U., Bentley, Y., 2017. The debate on flexibility of environmental regulations, innovation capabilities and financial performance - A novel use of DEA. Omega 0, 1-8. doi:10. 1016/j. omega. 2017.02.006

Roberts, R.W., 1992. Determinants of corporate social responsibility disclosure: An application of stakeholder theory. Accounting, Organ. Soc. 17, $595-612$. doi : 10. 1016/0361-3682 (92) 90015-K

Russo, M. V., Fouts, P.A., 1997. A resource based perspective on corporate environmental performance and profitability. Acad. Manag. J. 40, 534-559. doi:10. 2307/257052

Seroa da Motta, R., 2006. Analyzing the environmental performance of the Brazilian industrial sector. Ecol. Econ. 57, 269 - 281. doi:10. 1016/j. ecolecon. 2005. 04. 008

Shen, J., Dennis, Y., Yang, Z., 2017. The impact of environmental regulations on the location of pollution- intensive industries in China. J. Clean. Prod. 148, 785 794. doi:10. 1016/j. jclepro. 2017.02. 050

Tang, S. Y., Lo, C.W.H., Fryxell, G.E. , 2003. Enforcement styles, organizational commitment, and enforcement effectiveness: An empirical study of local 
environmental protection officials in urban China. Environ. Plan. A 35, 75 - 94. doi : 10. 1068/a359

Telle, K., 2006. "It pays to be green” - A premature conclusion? Environ. Resour. Econ. 35, 195 - 220. doi:10. 1007/s10640-006-9013-3

Telle, K., Larsson, J., 2007. Do environmental regulations hamper productivity growth? How accounting for improvements of plants' environmental performance can change the conclusion. Ecol. Econ. 61, 438 - 445. doi:10. 1016/j. ecolecon. 2006. 03. 015

Testa, F., Iraldo, F., Frey, M., 2011. The effect of environmental regulation on firms' competitive performance: The case of the building \& construction sector in some EU regions. J. Environ. Manage. 92, 2136 - 2144. doi:10. 1016/j. jenvman. 2011. 03. 039

Thomas, A., 2001. Corporate environmental policy and abnormal stock price returns: An empirical investigation. Bus. Strateg. Environ. 10, $125-134$.

Tong, Z., 2009. Reflections on environmental mass incidents in China. China Environ. Yearb. $235-248$.

Trumpp, C., Guenther, T., 2015. Too little or too much? Exploring U-shaped relationships between corporate environmental performance and corporate financial performance. Bus. Strateg. Environ. 35, 1269 - 1274. doi:10.1002/bse. 1900

Wagner, M., 2005. How to reconcile environmental and economic performance to improve corporate sustainability: Corporate environmental strategies in the European paper industry. J. Environ. Manage. 76, 105 - 118. doi:10. 1016/j. jenvman. 2004. 11. 021

Wagner, M., Phu, N. Van, Azomahou, T. T., Wehrmeyer, W., Van, P. N. , Wagner, M., 2002. Determinants of environmental and economic performance of firms: An empirical analysis of the European paper industry. Corp. Soc. Responsib. Environ. Manag. 9, 133 - 146. doi:10. 1002/csr. 22

Wagner, M. , Schaltegger, S., 2004. The effect of corporate environmental strategy choice and environmental performance on competitiveness and economic performance: An empirical study of EU manufacturing. Eur. Manag. J. 22, $557-572$. doi:10. 1016/j. emj. 2004. 09. 013

Wang, Y., Shen, N., 2016. Environmental regulation and environmental productivity: The case of China. Renew. Sustain. Energy Rev. 62, $758-766$ doi:10. 1016/j. rser. 2016. 05. 048

Watson, K., Klingenberg, B., Polito, T., Geurts, T. G., 2004. Impact of environmental management system implementation on financial performance: A comparison of two corporate strategies. Manag. Environ. Qual. An Int. J. 15, $622-628$. doi: 10. 1108/14777830410560700

Wei, Z., Shen, H., Zhou, K.Z., Li, J. J., 2017. How does environmental corporate social responsibility matter in a dysfunctional institutional environment? Evidence from China. J. Bus. Ethics 140, 209 - 223. doi:10. 1007/s10551-015-2704-3

Wesselink, A., Paavola, J., Fritsch, 0., Renn, 0., 2011. Rationales for public participation in environmental policy and governance: Practitioners' perspectives. Environ. Plan. A 43, 2688 - 2704. doi:10. 1068/a44161

Xie, R., Yuan, Y., Huang, J., 2017. Different types of environmental regulations and heterogeneous influence on "Green" productivity: Evidence from China. Ecol. Econ. 132, $104-112$. doi:10. 1016/j. ecolecon. 2016. 10. 019

Yang, C.H., Tseng, Y.H., Chen, C.P., 2012. Environmental regulations, induced R\&D, and productivity: Evidence from Taiwan's manufacturing industries. Resour. Energy Econ. 34, 514-532. doi:10. 1016/j. reseneeco. 2012. 05. 001

Yang, L., Wang, K. L., 2013. Regional differences of environmental efficiency of China' s energy utilization and environmental regulation cost based on provincial panel data and DEA method. Math. Comput. Mode1. 58, 1074 - 1083. doi:10. 1016/j. mcm. 2012. 04.004

Yu, W., Ramanathan, R., 2015. An empirical examination of stakeholder pressures, green operations practices and environmental performance. Int. J. Prod. Res. 53, 6390 6407. doi:10. 1080/00207543. 2014.931608

Yu, W., Ramanathan, R., Nath, P., 2017. Environmental pressures and performance: An analysis of the roles of environmental innovation strategy and marketing capability. Technol. Forecast. Soc. Chang. 117, $160-169$. doi:10.1016/j. techfore. 2016. 12. 005

Zhang, B., Bi, J., Yuan, Z., Ge, J., Liu, B., Bu, M., 2008. Why do firms engage in environmental management? An empirical study in China. J. Clean. Prod. 16, 1036 - 
1045. doi:10. 1016/j. jclepro. 2007.06. 016

Zhao, J., Hong, J., Chen, W., Song, Z., Wang, Q., Ma, C., 2016. Life cycle assessment of lignite pyrolysis: A case study in China. J. Clean. Prod. 113, $548-556$. doi:10. 1016/j. jclepro. 2015. 11. 088

Zhao, X. , Sun, B. , 2016. The influence of Chinese environmental regulation on corporation innovation and competitiveness. J. Clean. Prod. 112, $1528-1536$. doi:10. 1016/j. jclepro. 2015.05. 029

Zhao, X. L., Yin, H.T., Zhao, Y., 2015a. Impact of environmental regulations on the efficiency and C02 emissions of power plants in China. Appl. Energy 149, $238-247$. doi:10. 1016/j. apenergy. 2015. 03. 112

Zhao, X. L., Zhao, Y., Zeng, S.X., Zhang, S. F., 2015b. Corporate behavior and competitiveness: Impact of environmental regulation on Chinese firms. J. Clean. Prod. 86, 311 -322. doi:10. 1016/j. jclepro. 2014. 08. 074

Zheng, D., Shi, M. , 2017. Multiple environmental policies and pollution haven hypothesis: Evidence from China's polluting industries. J. Clean. Prod. 141, $295-304$ doi:10. 1016/j. jclepro. 2016.09. 091 